\title{
A Study on Learning Effects of Integrating Information Technology into Electronics Curriculum Teaching
}

\author{
Yu-Cheng Liao, Chin-Wen Liao, Chi-Hsiang Chen, and Yun-Hua Liao
}

\begin{abstract}
The study adopted the quasi-experimental design with nonequivalent groups to investigate learning effects of integrating information technology into electronics curriculum teaching. The study subjects were divided into two groups, the control group and the experimental group. There were 52 students in the control group who were taught by the conventional teaching approach. There were 48 students in the experimental group who were educated by the way of information technology integrated into teaching. The experimental teaching has lasted for 8 weeks, and the findings were stated as follows. First, on electronics curriculum learning, the experimental group demonstrated a significantly higher effect than the control group. Secondly, on electronics curriculum learning, students with low cognitive load demonstrated significantly better effect than students with high cognitive load. Thirdly, on learning results of electronics curriculum, the influencing factors included the teaching model, cognitive load, and previous experiences. Fourthly, students in the experimental group have obviously enhanced on learning effects of electronics curriculum.
\end{abstract}

Index Terms-Information technology integrated into teaching, e-learning, interactive response system (IRS), cognitive load, learning effect.

\section{INTRODUCTION}

Thurow, a world-famous economist, pointed out (Building Wealth) that the 21 st century is a knowledge-based economic era with a height information technology. The knowledge-based economy mainly emphasizes the spirit of innovation which comes from cultural literacy; cultural literacy needs good cultural environment. Education offers the most important basis for cultural environment [1]. Nations around the world in response to globalization competition have information technology integrated into teaching as the focus of school education. Use information technology integrated into teaching well to make students acquire effective knowledge that will be a new issue of education [2].

Digital materials are mostly known characteristics and functions such as integration, interaction, affinity,

Manuscript received April 20, 2015; revised June 29, 2015. This work was supported in part by the Ministry of Science and Technology under Grants MOST 103-2511-S-018-018.

Y.-C. Liao is with the Department of Electrical Engineering, National Taiwan University of Science and Technology, Taiwan (e-mail: ms0605521@yahoo.com.tw).

C.-W. Liao and C.-H. Chen are with the Department of Industrial Education and Technology, National Changhua University of Education (NCUE), Taiwan (e-mail: tcwliao@cc.ncue.edu.tw, ccicjs2011@gmail.com).

Y.-H. Liao is with the Department of Civic Education and Leadship, National Taiwan Normal University, Taiwan (e-mail: grapesherry@yahoo.com.tw). non-linearity, real-time, and the virtual [3]. It is important to select the appropriate teaching strategies to play the benefits of tool-assisted learning in order to achieve good learning results [4]. The process of education is a cycle which is composed of assessment, instruction, re-assessment and re-instruction. Assessment in this case acts like a bridge across a whole teaching activity [5]. Many studies have worked on introducing the interactive response system (IRS) into teaching in the classroom, especially in those science related courses or large classes [6]. IRS is a learning environment of information technology application. In the classroom, learning efficacy can be elevated by transmitting, collecting, recording, and presenting responses of students [7] as well as giving instantaneous assessments and feedbacks [8].

Information technology integrates texts, sounds, pictures, video, animation and other multimedia designs into the instruction to enhance learning efficacy of learners [9]. Nevertheless, if the teaching materials are poorly designed or improper, features of multimedia and their benefits on learning efficacy may be lost [10]. Sweller pointed out that if the design of teaching materials or learning procedure far exceeds the working memory capacity of learners, their cognitive load will be increased, which can affect their comprehension, learning, and problem-solving abilities [11].

According to the above-mentioned, information technology integrated into teaching provides multiple channels of stimulation and allows students to use various senses in learning, creating a multi-intelligence learning [12].

Therefore, the teaching model of information technology integrated into instruction is an irresistible trend. However, there are only few studies on the application of information technology integrated into teaching for vocational education, which is definitely an important but neglected area. By means of information technology integrated into electronics courses; this study investigates learning effects of students under different teaching models and understands the influences of cognitive load to learning results.

\section{RESEARCH DESIGN AND IMPLEMENTATION}

The study variables include the followings. Control variables are variables to be controlled so the experiment results will not be affected. In this study, these variables are the basic capacity of the students, the teaching capacity of the instructor, the teaching materials, and the evaluation tools. Independent variables in the study are chosen based on the objectives of the study, i.e., the effect of different teaching models on the learning efficacy of vocational high school students taking the electronics course. In this study, a 
quasi-experimental design was adopted, and the students were divided into the experimental and the control groups to be taught by different teaching models. For dependent variables, they are used to explore differences in cognitive learning, learning attitude, and learning satisfaction between experimental and the control groups taking the electronics course. The research design and model are presented in Table I below.

TABLE I: EXPERIMENT DESIGN AND MODEL

\begin{tabular}{lcccc}
\hline Group & Pre-test & Experiment & Post-test & Retention test \\
\hline Experimental & $\mathrm{Y}_{1}$ & $\mathrm{X}_{1}$ & $\mathrm{Y}_{2}$ & $\mathrm{Y}_{5}$ \\
\hline Control & $\mathrm{Y}_{3}$ & $\mathrm{X}_{2}$ & $\mathrm{Y}_{4}$ & $\mathrm{Y}_{6}$ \\
\hline Experimental group: $\mathrm{Y}_{1}, \mathrm{X}_{1}, \mathrm{Y}_{2}, \mathrm{Y}_{5}$ & & \\
Control group: $\mathrm{Y}_{3}, \mathrm{X}_{2}, \mathrm{Y}_{4}, \mathrm{Y}_{6}$ & & \\
$\mathrm{Y}_{1}, \mathrm{Y}_{3}$ : Pre-test & & & \\
$\mathrm{Y}_{2}, \mathrm{Y}_{4}$ : Post-test & & \\
$\mathrm{Y}_{5}, \mathrm{Y}_{6}$ : Retention test & & \\
$\mathrm{X}_{1}$ : Teaching model: integrating information technology into instruction \\
$\mathrm{X}_{2}$ : Teaching model: conventional approach
\end{tabular}

The research tools used in the study include the cognitive learning scale, the learning attitude scale, and the learning satisfaction scale. These scales were developed based on content validity, and during the development, the vocation high school instructor and experts with abundant experiences discussed the appropriateness and the wording of the questions and then modified the questions before they were finalized. The reliability of each scale is presented below [13]. For the internal consistency of the cognitive learning scale, it has a KR20 coefficient of 0.876 . For the internal consistency of the learning attitude scale, it has a Cronbach's $\alpha$ of 0.935 . For the internal consistency of the learning satisfaction scale, it has a Cronbach's $\alpha$ of 0.866 .

The experiment was implemented as below. A post-test was conducted on March 2014, and the subjects were students of a national vocation high school. The post-test was used to assess the basic capacity of the students, and the results were used to eliminate impacts from students' basic skills on cognitive learning, learning attitude, and learning satisfaction related to the electronics course. By doing so, the investigators ensured that all subjects would go through the experiment from the same starting point. Between April and May 2014, experimental teaching was conducted. The control group received the conventional teaching model, while the experimental group received the teaching model with information technology integrated. In June 2014, students from the control group and the experimental groups received the post-learning test. In the test, they were asked to fill out the cognitive learning scale, the learning attitude scale, and the learning satisfaction scale related to the course they took on electronics. In mid-June of 2014, students from the control group and the experimental groups received the retention test. In the test, they were asked to fill out the cognitive learning scale, the learning attitude scale, and the learning satisfaction scale related to the course they took on electronics. The test was used to understand the learning retention effect of the two teaching models on students' learning efficacy.

\section{DATA ANALYSIS AND DISCUSSION}

The objective here is to statistically analyze data collected from the pre-learning, the post-learning, and the retention tests, to test the hypotheses, and to analyze the results for discussion.

\section{A. Analysis of the Profile of the Sample}

The data acquired were analyzed using frequency distribution $(N)$ and percentage $(\%)$ to understand the basic profile of the sample. For teaching models (see Table II), there were 48 subjects in the experiment group (48\%) and 52 people in the control group (52\%). A total of 100 subjects participated in the experiment, and the number of subjects between the two groups were similar. For gender (see Table II), there were 99 males and one female, and therefore, most of the subjects were males.

TABLE II: ANALYSIS OF STUDENT PROFILE

\begin{tabular}{cccc}
\hline Variable & Group & Size $(N)$ & Percentage $(\%)$ \\
\hline \multirow{2}{*}{ Teaching model } & Experimental & 48 & 48 \\
\cline { 2 - 4 } & Control & 52 & 52 \\
\hline \multirow{2}{*}{ Gender } & Male & 99 & 99 \\
\cline { 2 - 4 } & Female & 1 & 1 \\
\hline \multirow{2}{*}{$N=100$} & & &
\end{tabular}

\section{B. Analysis of Effects of Different Teaching Models on Electronics Course Learning Efficacy}

The effect of different teaching models on electronics course learning efficacy comprises the cognitive, the attitude, and the satisfaction aspects, and each aspect is described below. For the cognitive aspect, a significant difference between the teaching models was found $(F=14.013, p<.05)$. Post-hoc analysis results showed that students in the experimental group got a higher cognitive learning score than those in the control group did. A significant difference was observed on the learning attitude between the two groups (Wilks' $\Lambda=0.340, p<.01$ ). It can be found from the post-hoc comparison that the experimental group showed a higher learning attitude than the control group did. A significant difference was also observed between the two groups on their learning satisfaction of the electronics course (Wilks' $\Lambda=0.841, p<.01)$. It can be found from the post-hoc comparison that the experimental group showed a significant greater learning satisfaction than the control group did. The results here are consistent with the results from $\mathrm{Li}$ [14], and from Liao [15].

\section{Analysis of Effects of Different Levels of Cognitive Load on Electronics Course Learning Efficacy}

The effect of different levels of cognitive load on electronics course learning efficacy comprises the cognitive, the attitude, and the satisfaction aspects, and each aspect is described below. For the cognitive aspect, a significant difference between different cognitive load levels was found $(F=30.665, p<.01)$. Post-hoc analysis results showed that students with lower cognitive load got a higher learning cognitive score than students with higher cognitive load. A significant difference was observed on the learning attitude of the electronics course between high vs. low cognitive load (Wilks' $\Lambda=0.476, p<.01$ ). It can be found from the post-hoc comparison that students with low cognitive load showed a better learning attitude than students with high cognitive load. A significant difference was also observed between the two 
cognitive levels on electronics course learning satisfaction (Wilks' $\Lambda=0.526, p<.01$ ). It can be found from the post-hoc comparison that students with lower cognitive load showed a significant greater learning satisfaction than those with higher cognitive load. The results here are consistent with the results from $\mathrm{Li}$ [14], and from Liao [15].

\section{Pathway Analysis of Models and Factors Affecting Students' Electronics Course Learning Efficacy}

The framework of the study was developed based on learning efficacy related factors proposed by experts and scholars as well as on findings from the literature. A full model was constructed. With statistical testing taken into consideration, a restriction model was constructed for factors affecting students' electronics course learning efficacy to explore interactions among factors related to students' electronics course learning efficacy. The results are presented below.

E. Analysis of the Effect of Teaching Models on the Pre-learning and Post-test Results of Electronics Course Cognitive Learning

The study used the paired t-test to examine pre- and post-learning differences in electronics course cognitive learning in the control group and in the experimental group. The paired t-test results suggest that for the experiment group, the difference between the pre-learning and the post-learning scores on cognitive learning is statistically significant $(t=3.609, p<.01)$. For the control group, however, the difference is not statistically significant $(t=0.064, p>.05)$. This finding suggests that the cognitive learning effect in the experimental group was improved by the teaching activity. This finding is consistent with [16]-[18].

TABLE III: ANALYSIS OF THE RELATIONSHIP BETWEEN THE THREE ASPECTS OF INTEGRATING INFORMATION TECHNOLOGY INTO INSTRUCTION AND THE LEARNING EFFICACY OF DIFFERENT LEARNING UNITS OF THE ELECTRONICS COURSE

\begin{tabular}{|c|c|c|c|}
\hline Chapter & Unit & Knowledge domain & Aspect relationship \\
\hline \multirow{6}{*}{ 1. Operational amplifier } & 1. About the ideal operational amplifier & \multirow{5}{*}{$\begin{array}{l}\text { Knowledge } \\
\text { Comprehension } \\
\text { Application }\end{array}$} & $(\mathrm{C})>(\mathrm{A})$ \\
\hline & 2. Characteristics and parameters of operation amplifier & & $\begin{array}{l}(\mathrm{C})>(\mathrm{A}) \\
(\mathrm{C})>(\mathrm{B})\end{array}$ \\
\hline & 3. Inverting and non-inverting amplifier & & $\begin{array}{l}(\mathrm{C})>(\mathrm{A}) \\
(\mathrm{C})>(\mathrm{B})\end{array}$ \\
\hline & 4. Adder and subtracter & & $(\mathrm{C})>(\mathrm{A})$ \\
\hline & 5. Differentiator and integrator & & $(\mathrm{C})>(\mathrm{A})$ \\
\hline & 6. Comparator & Analysis & Non-significant \\
\hline \multirow{6}{*}{$\begin{array}{l}\text { 2. Fundamental oscillation } \\
\text { circuit }\end{array}$} & 7. Sine wave generating circuit & \multirow{3}{*}{$\begin{array}{l}\text { Knowledge } \\
\text { Comprehension } \\
\text { Application }\end{array}$} & $(\mathrm{C})>(\mathrm{B})$ \\
\hline & 8. Multivibrator & & $(\mathrm{C})>(\mathrm{A})$ \\
\hline & 9. Schmitt trigger & & $(\mathrm{C})>(\mathrm{A})$ \\
\hline & 10. Square wave generating circuit & \multirow{2}{*}{ Analysis } & Non-significant \\
\hline & 11. Triangle wave generating circuit & & Non-significant \\
\hline & 12. 555 Timer oscillator circuit & Synthesis & $(\mathrm{B})>(\mathrm{A})$ \\
\hline
\end{tabular}

Source: Prepared by the study

Note: (A) Text on the web page; (B) Multimedia on the web page; (C) Real-time IRS

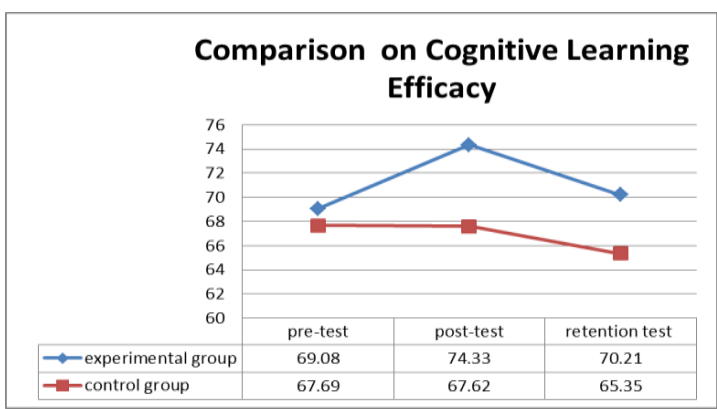

Fig. 1. Comparison on cognitive learning efficacy.

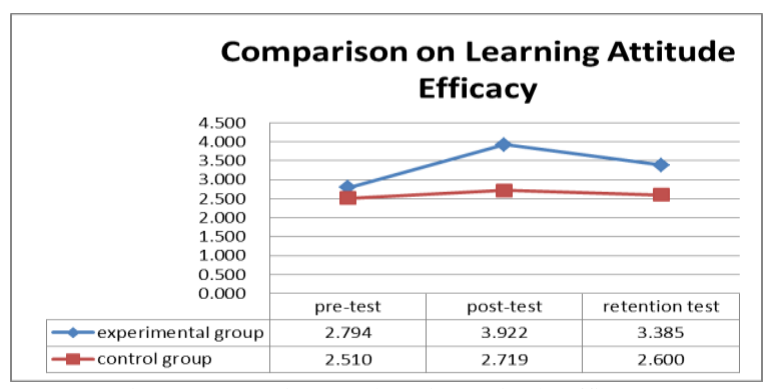

Fig. 2. Comparison on learning attitude efficacy.

See Fig. 1 for the comparison on cognitive learning efficacy, Fig. 2 for comparison on learning attitude efficacy, and Fig. 3 for comparison on learning satisfaction efficacy. In Fig. 4 the restriction model of factors is drawn based on the standardized estimates from pathway analysis.

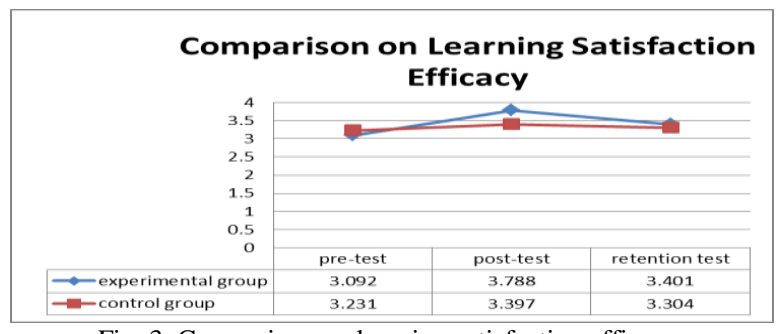

Fig. 3. Comparison on learning satisfaction efficacy.

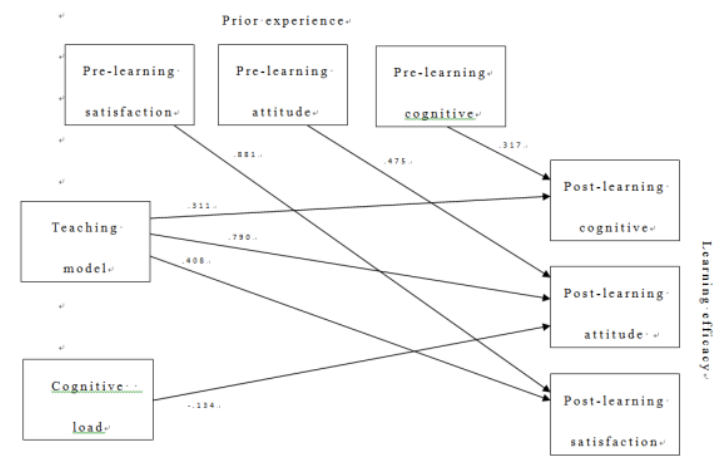

Fig. 4. Restriction model of factors affecting electronics course learning efficacy.

\section{F. Post-learning Questionnaire Survey on Integrating Information Technology into Instruction}

Overall, students of the experimental group considered that IRS has the greatest impact on electronics course learning 
efficacy. Table III below shows impacts from the three aspects of the teaching model with information technology integrated into instruction ((A) text on the web page, (B) multimedia on the web page, and (C) IRS) on the learning efficacy of each learning unit of the electronics course in the experimental group. It was found that IRS has a greater impact on the basic capacity including knowledge, comprehension and application of the cognitive domain but for cognitively more complicated analysis capacity, IRS was found to have little or no impact. As for integrating fragments of concepts or knowledge, principles and mechanisms, and facts into a new and more general capacity, multimedia on web pages is partially better than text on web pages. The results are consistent with results shown by Tsai, Chen, and $\mathrm{Ku}$ [19]-[21].

\section{CONCLUSION AND SugGESTIONS}

\section{A. Conclusion}

According to the study objectives, hypothesis testing results, and key research findings, the investigators summarized and discussed the information and made the following conclusions.

\section{1) The teaching model with information technology} integrated into teaching is significantly more effective than the conventional teaching model in terms of students' electronics course learning efficacy

For students taught by the teaching model with information technology integrated, their cognitive learning, learning attitude, and learning satisfaction were significantly better than those of students taught by the conventional way. Furthermore, the teaching model with information technology integrated was found to have the greatest impact on the learning attitude, followed by the learning satisfaction and cognitive efficacy of learning.

\section{2) Cognitive load has a significant effect on students' electronic course learning efficacy}

Students with low cognitive load showed better electronic course cognitive learning, learning attitude, and learning satisfaction than those with high cognitive load. In other words, students' electronics course learning efficacy is affected by cognitive load.

3) Teaching model, cognitive load, and prior experience are factors affecting electronics course learning efficacy

Pathway analysis results of the restriction model suggest that the teaching model variable can directly affect learning efficacy, and the greatest effect is on learning attitude. In addition, cognitive load can directly affect learning attitude. Overall, factors affecting electronics course learning efficacy are teaching model, cognitive load, and prior experience.

4) Students taught by the teaching model with information technology integrated showed significantly improved electronics course learning efficacy

Students taught by the teaching model with information technology integrated showed significantly better post-learning electronics grades than the pre-learning electronics grades. In other words, integrating information technology into instruction can result excellent learning efficacy.

5) Students taught by the teaching model with information technology integrated suggested that IRS has the greatest impact on electronics course learning efficacy

Students taught by the teaching model with information technology integrated suggest that IRS has the greatest impact on electronics course learning efficacy, meaning that when a learning unit is more oriented toward the basic cognitive aspect, the use of IRS can produce a greater effect. As for learning units that are more about integrating learned fragments of concepts or knowledge, principles and mechanisms, and facts into a new, overall, and general capacity, it is better to use web page multimedia.

\section{B. Suggestions}

According to the findings and conclusion of the study, the investigators provide suggestions for the education administrative authorities, schools, teachers' teaching design and implementation, and subsequent research. These suggestions can be referred to for integrating information technology into electronics course teaching in vocational high schools and continuous education programs or for carrying out subsequent research.

\section{1) Suggestions for education administrative authorities}

1) It is recommended to have information technology integrated into instruction included in the teacher training courses.

2) It is useful to implement seed teacher training for integrating information technology into instruction.

3) It is important to continuously develop e-teaching materials for other courses.

4) It is a good idea to hold workshops on integrating information technology into instruction routinely through Centers for the Study Area.

5) Teachers should be encouraged to develop their own digital teaching materials.

\section{2) Suggestions for schools}

1) The teaching model of information technology integrated into instruction should be promoted for electronics courses.

2) School administrative departments should fully support teachers to adopt the teaching model of information technology integrated into instruction.

3) Suggestions for teachers on teaching design and implementation

1) For giving electronics related courses, it is important to consider the use of the teaching model of information technology integrated into instruction.

2) Teachers should have an idea of students' cognitive load and adopt an appropriate teaching model accordingly.

3) Teachers should use reinforcement to encourage students to use the resource network set up for electronics courses to facilitate learning.

4) It is important to value the teaching model and the cognitive load as well as the entering behavior of students.

5) When adopting the teaching model of information 
technology integrated into instruction, it is important to consider the learning efficacy of different teaching units.

\section{4) Suggestions for future research}

1) Research methods: If the environment or equipment permits, researchers can adopt a true experimental design to further explore the learning behavior of students under technology information integrated course instruction.

2) Research tools: Subsequent studies can adopt other scales or integrate other methods, such as observation and in-depth interview, to acquire more in-depth research results.

3) Research subjects: Researchers of subsequent studies can choose full-time students or students of different majors or study areas as the subjects for expanding the research further.

4) Research topics: Researchers of subsequent studies can consider different types of learning motivation, personality traits, self-efficacy and other personal factors to test if differences exist among them in electronics course learning efficacy. In addition, one can explore learning in other courses like fundamental electronics, digital logics, and electronic circuits.

5) Statistical analysis: It is recommended that subsequent researchers can adopt a multi-factor experimental design to explore influences from chosen variables in a greater depth, and the information can be referred to for planning the implementation of information technology integrated instruction in the future.

\section{ACKNOWLEDGMENT}

The project was funded by the Ministry of Science and Technology under Grants MOST 103-2511-S-018-018.

\section{REFERENCES}

[1] C. Wu, Education Policies for the Knowledge-Based Economic Era, Taipei, Taiwan: Commonwealth, 2000.

[2] J. T. Fan, "A review of the teaching obstacles and the available strategies in integrated information technology instruction," Chung Hua Journal of Humanities and Social Sciences, vol. 3, pp. 32-55, 2005.

[3] H. C. Li, "A study of applying the video materials based on task analysis approach to meal preparation training on junior high school students with mental retardation," Master thesis, Graduate Institute of Technological and Vocational Education, National Taipei University of Technology, Taiwan, 2010.

[4] C. H. Yang, "Vision for heading toward the new century: Open education and the media from internet," Distance Education, vol. 15, pp. 75-84, 2000.

[5] J. L. Huang, "The study of the influence of CAL software on middle school students' learning of buoyancy concept," Master thesis, College of Extension Education, National Changhua University of Education, Taiwan, 2003

[6] C. Fies and J. Marshall, "The C3 framework: Evaluating classroom response system interactions in university classrooms," Journal of Science Education and Technology, vol. 17, no. 5, pp. 483-499, 2008.

[7] R. M. Gagne, The Conditions of Learning, 3rd ed., Holt, Rinehart \& Winston, 1997

[8] S. Cotner, B. Fall, S. Wick, J. Walker, and P. Baepler, "Rapid feedback assessment methods: Can we improve engagement and preparation for exams in large-enrollment courses?" Journal of Science Education and Technology, vol. 17, no. 5, pp. 437-443, 2008.

[9] K. H. Huang, Principles of Teaching, Taipei: Shtabook, 1999

[10] C. Lin and H. Y. Li, "A study of media delivery for web-based instruction," in Proc. 2002 Open and Remote Education Academic Media Conference, 2002, pp. 35-71.

[11] J. Sweller, "Cognitive load theory, learning difficulty, and instructional design," Learning and Instruction, vol. 4, pp. 295-312, 1994.
[12] T. Li, "The effectiveness of a multimedia Morse Code learn-by-doing system on written work for persons with severe physical disabilities," Doctoral dissertation, The Johns Hopkins University, Baltimore, MD, 1998.

[13] S. Y. Kuo, Psychology and Education Tests, Taipei: Chinghua, 1999.

[14] C. C. Li, "The study of asynchronous web-based assisted instruction for industrial safety courses in colleges and institutes of technological and vocational education," Ph.D. dissertation, Department of Industrial Education and Technology, National Changhua University of Education, Taiwan, 2001.

[15] W. C. Liao, "A research of factors influences mechanical skill development achievement in the vocational high school," Master thesis, College of Extension Education, National Changhua University of Education, Taiwan, 1999.

[16] H. C. Lin, "Internet-based research skills in the field of teaching: Taking the carpentry learning unit of junior high school life technology course," New instructor research report of National Taiwan Normal University (No. T9507000193), 2007.

[17] S. C. Li and Y. H. Yeh, "Cognitive load and multimedia teaching material design," Audio-Visual Education Bimonthly, vol. 47, no. 6, pp. 1-19, 2006.

[18] C. H. Li, Digital Teaching Material Seminar, Kaohsiung: FuHwa Senior High School, 2003.

[19] H. H. Tsai and A. Chang, "The impact of learning motivation on learning effect: The moderator of perceived leadership," Chung Hua Journal of Management, vol. 8, no. 4, pp. 1-18, 2007.

[20] C. W. Chen, "The effects of implementing interactive response system on fifth graders' English vocabulary learning achievement and learning attitude," Master thesis, Department of Children English Education, NTUE, 2009.

[21] S. H. Ku, "A study of the effect and relationship between mathematics attitude and self-regulated strategy with interactive response system for elementary school students," Master thesis, Department of Educational Technology of Tamkang University, 2011.

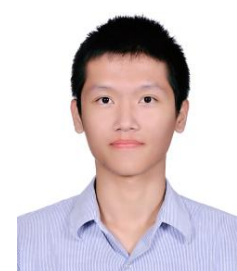

Yu-Cheng Liao graduated from National Taichung Industrial Vocational High School, and now is studying in National Taiwan University of Science and Technology. He did a research with Professor Liao in high school, and one of the researches he did with his colleagues won the National Exhibition of Science and Technology competition. His research interests are in science, technological and vocational education teacher education, energy education of technology, etc.

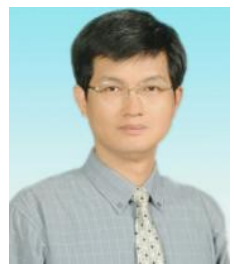

Chin-Wen Liao received both the M.S. and Ph.D. in industrial education from National Taiwan Norma University, Taiwan, R.O.C. in 1994 and 2002, respectively. Since August 2011, he has been a professor in the Department of Industrial Education and Technology at National Changhua University of Education (NCUE) in Taiwan, R.O.C. He teaches courses in technology and vocational education, energy education, course and teaching, organizational learning. His research interests are in technology and vocational education, teacher education, etc.

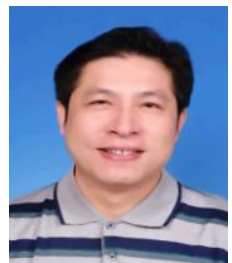

Chi-Hsiang Chen is a lecturer in the Department of Safety, Health and Environmental Engineering from HungKuang University, Taichung, Taiwan. He received the M.S. degree at the Department of Safety, Health and Environmental Engineering from HungKuang University, Taichung, Taiwan in 2008, and currently is a doctoral student at the Department of Industrial Education from National Changhua University, Changhua, Taiwan. He was a senior labor inspector in the Council of Labor Affair in Taiwan (from1988 to 2014). He has published articles in Journal of Loss Prevention in the Process Industries and others.

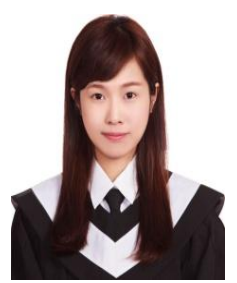

Yun-Hua Liao graduated from National Taichung Girl's Senior High School, and now is studying in the Department of Civic Education and Leadship, National Taiwan Normal University. She did a research with Professor Liao in College, and continue participate higher education research. Her research interests include technological and vocational education, teacher education, energy education of technology, public policy, civic education \& leadship, and learning organization. 